\title{
Numerical Simulation on Control of the Cutting Edge of the Scraper
}

\author{
Hiroshi Takahashi* and Yasuhiro Seyama** \\ * Dept. of Resources Eng., Tohoku Univ. Aramaki, Aoba-ku, Sendai 980-77 JAPAN \\ htaka@ecm1.earth.tohoku.ac.jp \\ ** Graduate School of Tohoku Univ., Dept. of Resources Eng., Aramaki, Aoba-ku, \\ Sendai 980-77 JAPAN
}

\begin{abstract}
This paper is concerned with the simulation of motion control of the cutting edge of the scraper. The task of flattening the ground was divided into two modes such as flattening and loading mode. It was confirmed that the accuracy of this simulation in the flattening mode by using the controller proposed here was about $3 \mathrm{~mm}$, which is much better than that of the expert operator. In the loading mode, the efficiency of the work was increased by controlling the height of the cutting edge so that the resistive force of excavation does not exceed the maximum tractive force.
\end{abstract}

\section{INTRODUCTION}

Recently, many working robots have been tried in several fields of industries such as mining and construction field in order to have workers safe and to increase the working efficiency. For example, a scraper is generally used for flattening the ground. However, an expert technique is necessary for flattening the ground and loading the excavated soil by the scraper because the operator of this machine needs to control the cutting edge and to drive the machine at the same time. Therefore, a load of the operator of scrapers is rather heavy, and the automation of the work of the scraper is desired. Some studies have been reported for the automation for some construction machines[1-4], but few studies have been reported for the automation of the scraper because of the complexity of the mechanism of the machine despite of its necessity.

Therefore, the objectives of this paper are to derive the motion controller of the cutting edge of the scraper in flattening the ground and loading operation of excavated soil, and to carry out the simulation of the excavation.

\section{MODEL ANALYSIS}

\subsection{Outline of the Scraper}

Figure 1 shows the outline of the scraper. A main body of the scraper is a large capacity container which is called "Bowl". The front and top of the bowl is open and "the cutting edge" is installed at the tip of the bottom of the bowl. The position of the bowl in 


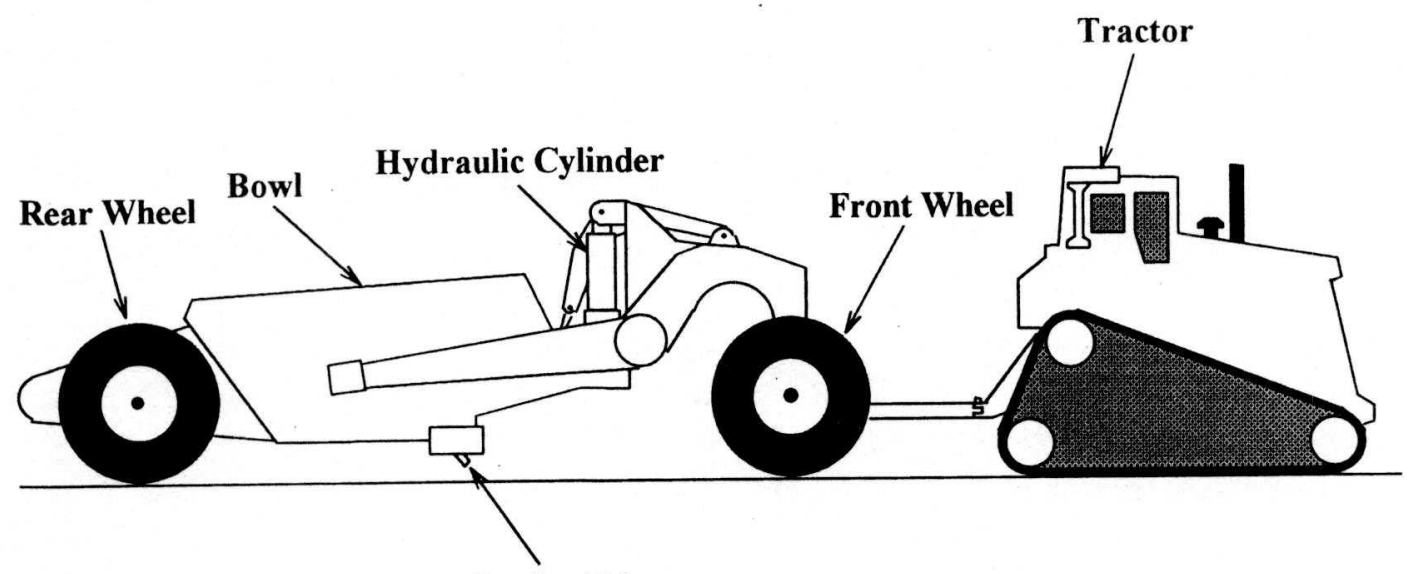

Cutting Edge

Fig. 1 Outline of the scraper

vertical direction is changed according to the change of rear and front wheel position. The cutting edge is also changed according to the change of the bowl position. Therefore, in order to carry out the task of flattening the ground, the height of the cutting edge have to be kept constant by controlling the length of the hydraulic cylinder regardless of the change of the front and rear wheel position. The flattening and loading operation is performed by advancing the scraper forward with penetrating the cutting edge into the ground. The excavated soil is loaded into the bowl from the cutting edge.

\subsection{Modeling of the Scraper}

Let the $\mathrm{X}$ axis be the target surface of the ground, and the motion of the scraper is assumed two dimensional. In this analysis, the mechanism of the scraper is modeled by the linkage, and Figure 2 shows the linkage of the scraper. Points 1 and 2 indicate the axis of the front and rear wheel, respectively. Point 6 indicates the cutting edge. In Figure 2, solid lines indicate the links whose length is not changed. Dashed lines indicate the links whose length is changed. $\phi_{1}-\phi_{3}$ are constant angles and $\theta_{1}-\theta_{11}$ are variable angles. Figure 2 shows that the position of the front wheel is higher than that of the rear wheel. If the scraper is set in a horizontal plane, the height of the front wheel, $y_{1}$ is equal to the height of the rear wheel, $\mathrm{y}_{2}$.

First, the equations to express the height of the cutting edge are derived for a given cylinder length. The height of the cutting edge, $\mathrm{y}_{\mathrm{c}}$ is expressed by Eq.(1).

$$
y_{C}=y_{2}-l_{26} \sin \theta_{3}
$$

Each parameter in Eq. (1) is expressed by following equations. Here, $l$ shows the length of the link whose length is not changed, and $L$ shows the length of the link whose length is changed. Subscripts show the point number in Figure 2.

$$
\begin{aligned}
& \theta_{5}=\cos ^{-1}\left(\frac{l_{34}^{2}+L_{C}^{2}+l_{35}^{2}}{2 l_{34} L_{C}}\right) \\
& \theta_{4}=\cos ^{-1}\left(\frac{l_{14}^{2}+l_{34}^{2}-l_{13}^{2}}{2 l_{14} l_{34}}\right)-\theta_{5}
\end{aligned}
$$


Axis of the Front Wheel

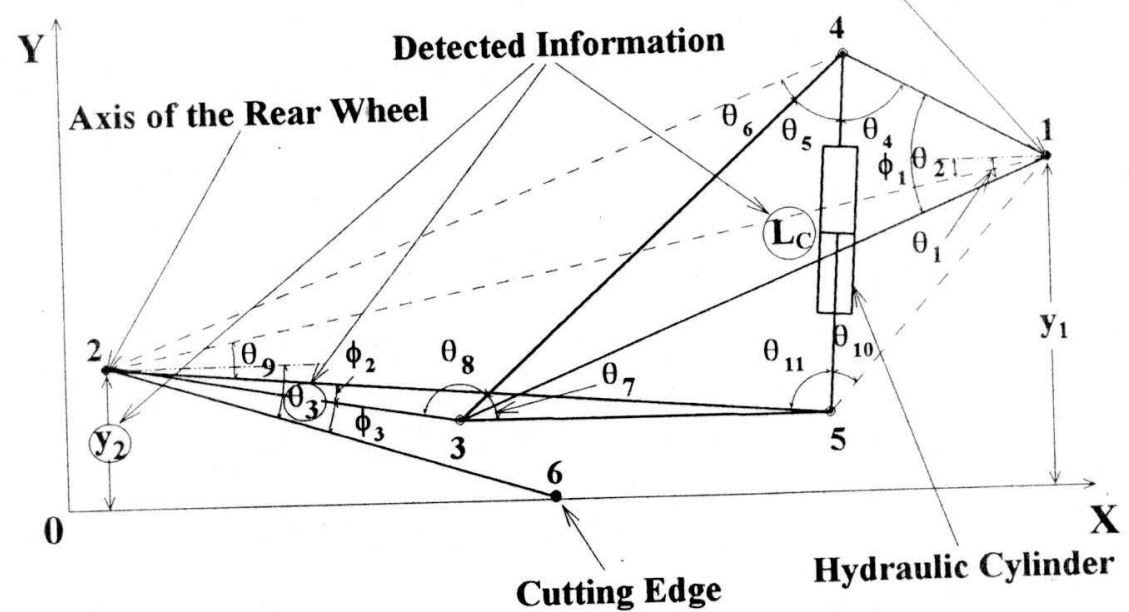

Fig. 2 Linkage of the scraper

$$
\begin{aligned}
\theta_{7} & =\cos ^{-1}\left(\frac{l_{34}^{2}+l_{35}^{2}-L_{C}^{2}}{2 l_{34} l_{35}}\right) \\
\theta_{5} & =\cos ^{-1}\left(\frac{l_{34}^{2}+L_{C}^{2}+l_{35}^{2}}{2 l_{34} L_{C}}\right) \\
L_{24} & =\sqrt{l_{23}^{2}+l_{34}^{2}-2 l_{23} l_{34} \cos \theta_{8}} \\
\theta_{6} & =\cos ^{-1}\left(\frac{L_{24}^{2}+l_{34}^{2}-l_{23}^{2}}{2 L_{24} l_{34}}\right) \\
L_{12} & =\sqrt{l_{14}^{2}+L_{24}^{2}-2 l_{14} L_{24} \cos \left(\theta_{4}+\theta_{5}+\theta_{6}\right)} \\
\theta_{2} & =\sin ^{-1}\left(\frac{y_{1}-y_{2}}{L_{12}}\right) \\
L_{15} & =\sqrt{l_{14}^{2}+L_{C}^{2}-2 l_{14} L_{C} \cos \theta_{4}} \\
\theta_{10} & =\cos ^{-1}\left(\frac{L_{15}^{2}+L_{C}^{2}-l_{14}^{2}}{2 l_{15} L_{C}}\right) \\
\theta_{10}+\theta_{11} & \geq \pi \\
\theta_{9} & =-\cos ^{-1}\left(\frac{l_{25}^{2}+L_{12}^{2}-L_{15}^{2}}{2 l_{25} L_{12}}\right) \\
\theta_{3} & =\phi_{2}+\phi_{3}-\theta_{2}+\theta_{9} \\
\theta_{11} & =\cos ^{-1}\left(\frac{l_{25}^{2}+L_{C}^{2}-L_{24}^{2}}{2 l_{25} L_{C}}\right) \\
+\theta_{11} & \leq \pi \\
\theta_{10} & \cos ^{-1}\left(\frac{l_{25}^{2}+L_{12}^{2}-L_{15}^{2}}{2 l_{25} L_{12}}\right) \\
\theta_{1} & \\
\text { If } &
\end{aligned}
$$


As shown above equations, if the length of the cylinder is given, the height of the cutting edge is uniquely determined.

Next, the procedure to obtain the length of the cylinder, $L_{\mathcal{C}}$ by using above equations for a given height of the cutting edge is as follows:

$$
\begin{aligned}
& \theta_{3}=\sin ^{-1}\left(\frac{y_{2}-y_{C}}{l_{26}}\right) \\
& y_{3}=y_{2}-l_{23} \sin \left(\theta_{3}-\phi_{3}\right) \\
& y_{5}=y_{2}-l_{25} \sin \left(\theta_{3}-\phi_{2}-\phi_{3}\right) \\
& \theta_{1}=\sin ^{-1}\left(\frac{y_{1}-y_{3}}{l_{13}}\right) \\
& x_{4}=x_{1}-l_{14} \cos \left(\phi_{1}-\theta_{1}\right) \\
& y_{4}=y_{1}+l_{14} \sin \left(\phi_{1}-\theta_{1}\right) \\
& x_{3}=x_{1}-l_{13} \cos \theta_{1} \\
& x_{2}=x_{1}-x_{3}-l_{23} \cos \left(\theta_{3}-\phi_{3}\right) \\
& x_{5}=x_{2}+l_{25} \cos \left(\theta_{3}-\phi_{2}-\theta_{3}\right) \\
& L_{C}=\sqrt{\left(x_{5}-x_{4}\right)^{2}+\left(y_{5}-y_{4}\right)^{2}}
\end{aligned}
$$

As shown above equations, the length of the cylinder is determined for a given height of the cutting edge. If $y_{2}$ and $\theta_{3}$ are detected by some sensors, $y_{c}$ is obtained from Eq.(1).

Furthermore, all coordinates of the linkage and parameters are determined if $L_{c}$ is obtained. Therefore, the controller is made with variables $y_{2}, \theta_{3}$ and $L_{c}$ as detected information.

\section{CONTROLLER}

The purpose of introducing the controller in this analysis is to flatten the ground surface. However, in the actual work, the task of flattening the ground cannot be carried out if the maximum tractive force of the tractor exceeds the resistive force of excavation. In this study, the task of flattening the ground is divided into two modes, that is, flattening mode and loading mode, and the controller is made for each mode. The resistive force of excavation depends on several parameters such as the depth of the excavation, shape of the ground and weight of the excavated soil in the bowl. According to the advance of the work, the weight of the excavated soil in the bowl increases. Therefore, it is expected that the resistive force of excavation will exceed the maximum tractive force in the middle of the work. In this study, the simulation starts with flattening mode. Simultaneously, the resistive force is calculated and when the resistive force exceeds the tractive force, the mode is changed from flattening to loading and the simulation is continued.

\subsection{Flattening Mode}

As mentioned above, the detected parameters are $y_{2}, \theta_{3}$ and $L_{c}$. In this mode, the standard angle, $\theta_{3}$ is obtained from the detected $y_{2}$ and the target height of the ground for the cutting edge, as shown in Figure 3. The rate of oil transported into the cylinder is assumed to be expressed by

$$
Q=K_{p} \delta \theta_{3}+K_{i} \int_{0}^{t} \delta \theta_{3} d t+K_{d} \delta \dot{\theta}_{3}
$$




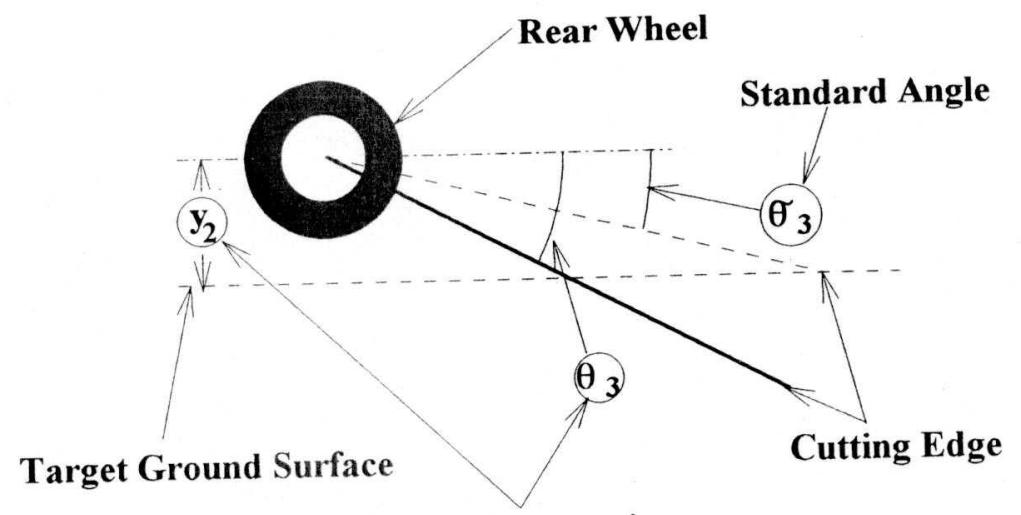

Detected Information

Fig. 3 Schematic diagram of the rear Wheel and Cutting Edge

where

$$
\delta \theta_{3}=\tilde{\theta}_{3}-\theta_{3} \quad \delta \dot{\theta}_{3}=\tilde{\dot{\theta}}_{3}-\dot{\theta}_{3} .
$$

$\mathrm{K}_{\mathrm{p}}, \mathrm{K}_{\mathrm{i}}$ and $\mathrm{K}_{\mathrm{d}}$ show the proportional, integral and derivative feedback gain, respectively.

\subsection{Estimation of the Resistive Force}

Estimation of the resistive force of excavation is very important because if the resistive force of excavation exceeds the maximum tractive force, the flattening work cannot be carried out more. Figure 4 shows the forces in the excavation process. $\mathrm{W}_{1}$ is the

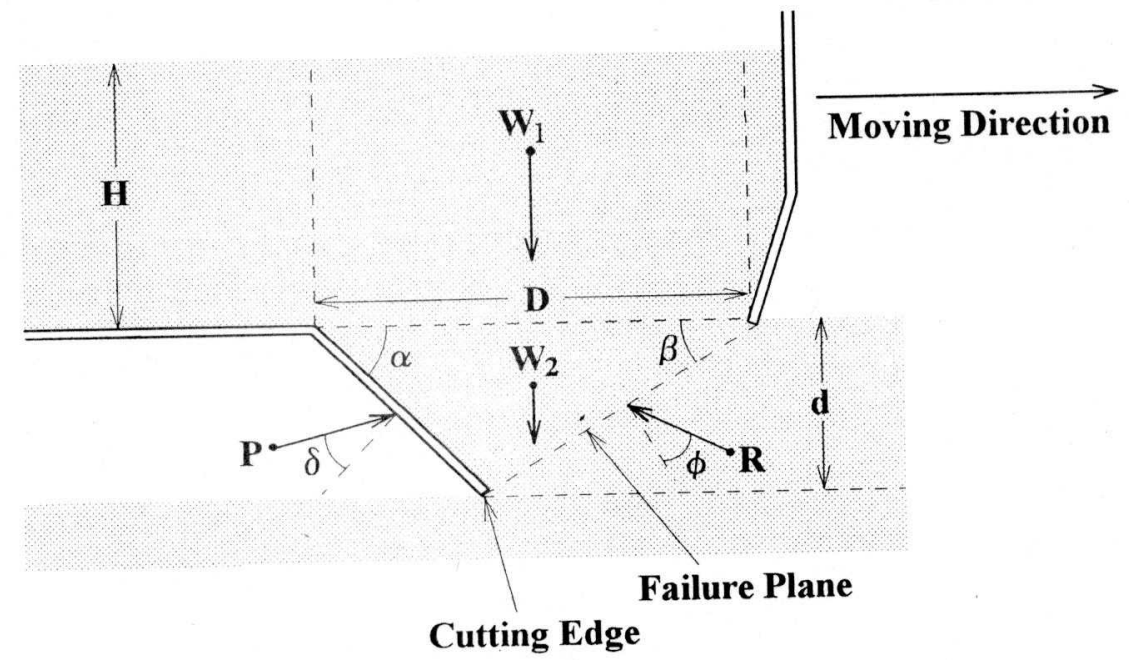

Fig. 4 Forces in the excavation process

surcharge load, $\mathrm{W}_{2}$ is the soil weight which is surrounded by the blade, failure plane and the surface of the ground. $\mathrm{R}$ is the resistive force and $\mathrm{P}$ is the inquired excavation force. The resistive force of excavation is the horizontal component of $\mathrm{P}$. By considering the force balance of $\mathrm{W}_{1}, \mathrm{~W}_{2}, \mathrm{R}$ and $\mathrm{P}$, the next equation is obtained.

$$
F=R \sin (\beta+\phi)=\left(\gamma d^{2} N_{\gamma H}+c d N_{C H}+W_{1} N_{q H}\right) b
$$


here, $\gamma$ is the weight of the excavated soil in the unit volume, $\mathrm{c}$ is the soil cohesion, $\mathrm{b}$ is the width of the bowl. $\mathrm{N}_{\gamma \mathrm{H}}, \mathrm{N}_{\mathrm{cH}}$ and $\mathrm{N}_{\mathrm{qH}}$ are called $\mathrm{N}$ coefficients and they are determined by the shape of the blade and physical properties of the soil. $\gamma, \mathrm{c}$ and $\mathrm{b}$ are obtained in advance prior to the work by investigating the soil properties. Therefore, unknown parameters in Eq. (27) are depth of excavation (d) and the height of the excavated soil in the bowl (H) which is needed to estimate the surcharge load $\left(\mathrm{W}_{1}\right)$.

\subsection{Loading Mode}

The threshold value is set for the resistive force of excavation in this simulation. If the estimated resistive force of excavation exceeds the threshold value, the flattening modes is stopped and the loading mode starts. In this mode, the following rate of oil is transported into the cylinder.

$$
Q=K_{f} \delta F \quad \delta F=\tilde{F}-F
$$

$\mathrm{K}_{\mathrm{f}}$ shows the feedback gain.

In the loading mode, since the cutting edge moves downward in the case of $\delta \mathrm{F}>0$, it is expected that the cutting edge exceeds the target ground surface and excavates the ground deeper(Figure 5). Therefore, if $\delta \mathrm{F}>0$ and the height of the cutting edge is less than the threshold value, the following oil rate is transported into the cylinder to avoid the deeper digging of the ground.

$$
Q=K_{p} \delta \theta_{3}
$$

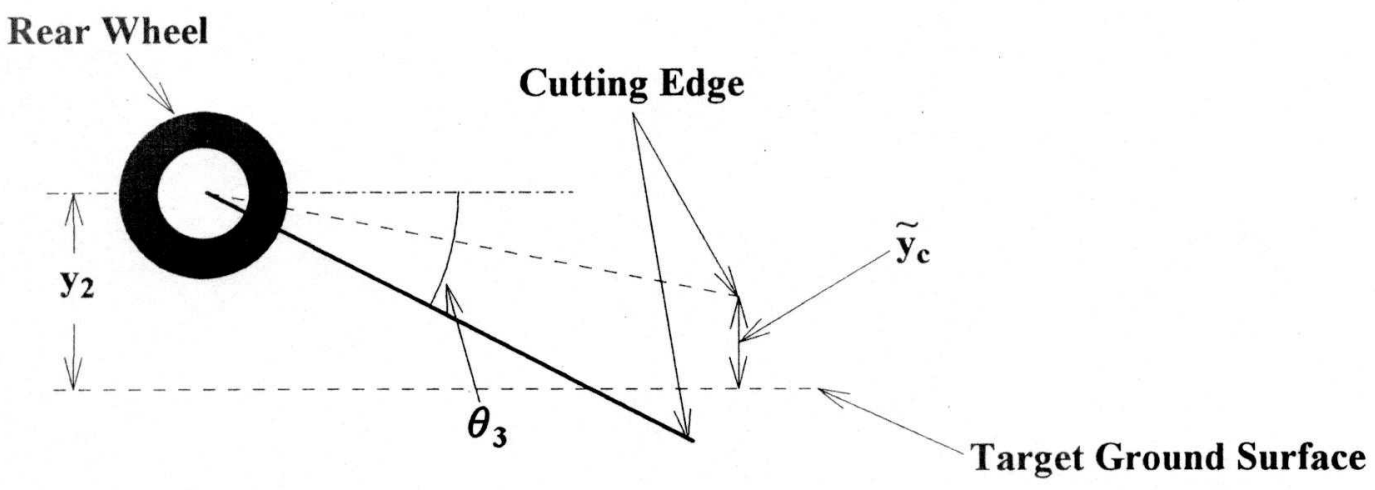

Fig. 5 Schematic diagram showing that the cutting edge excavate the target ground deeper

\section{SIMULATION RESULTS}

\subsection{Shape of the Initial Ground}

It is assumed that the initial ground surface where the scraper is set coincides with the target ground surface and let the height of this surface be zero. The surface of the ground to be flattened is assumed to be given by the following equation.

$$
y=0.045(3-\cos 1.4 x-\cos 0.9 x-\cos 0.5 x)
$$

where, $\mathrm{x}$ shows the moving distance of the scraper and $\mathrm{y}$ shows the height of the ground surface at $\mathrm{x}$. Figure 6 shows the shape of the ground before the work expressed by Eq. (30), which is considered in this simulation. 


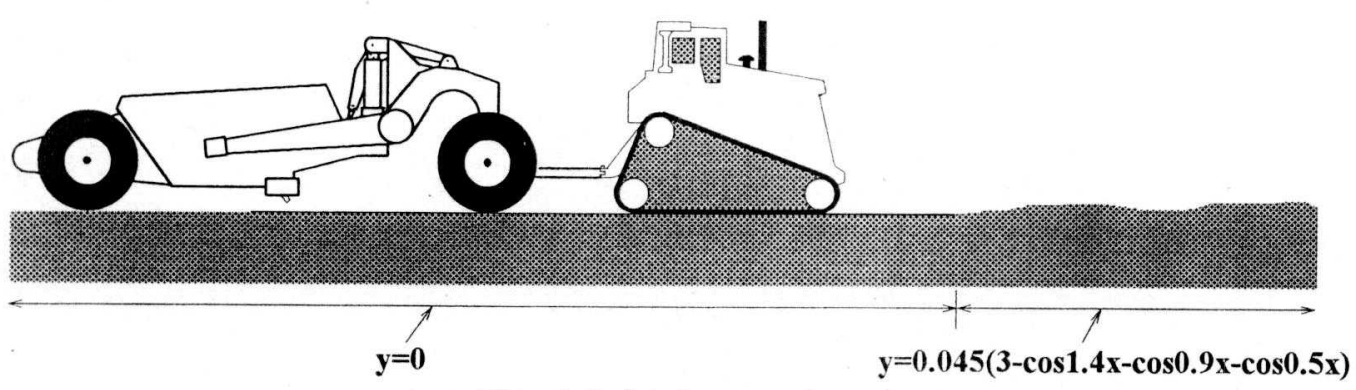

Fig. 6 Initial ground surface

\subsection{Disturbance}

When the oil rate expressed by Eq.(26) and Eq.(28) is transported into the cylinder, the theoretical change of the length of the cylinder in the minute time, $\Delta t$ should be

$(\Delta \mathrm{t}) \times($ oil rate $) /($ cross sectional area of the cylinder $)$

However, it is expected that the actual change of the cylinder length is less than the theoretical change length because of the resistive force in the up and down operation of the cylinder and the surcharge load in the bowl. Therefore, in this study, the change of the length of the cylinder in the time, $\Delta \mathrm{t}$ is assumed to be expressed by the next value.

$\mathrm{G} \cdot(\Delta \mathrm{t}) \times($ oil rate $) /($ cross sectional area of the cylinder $)$

Here, $\mathrm{G}$ is the disturbance and is less than unity. $\mathrm{G}$ is determined by the random number, and the range of $\mathrm{G}$ is assumed as follows:

For $\mathrm{G}_{\mathrm{a}}$ (extension of the cylinder)

In the case that the cutting edge does not excavate the ground: $\mathrm{G}_{\mathrm{a}}=0.95-1.0$

In the case that the cutting edge excavates the ground: $\quad \mathrm{G}_{\mathrm{a}}=0.6-1.0$

For $\mathrm{G}_{\mathrm{b}}$ (extraction of the cylinder)

In the case that the bowl is empty:

In the case that the bowl is not empty:

$\mathrm{G}_{\mathrm{b}}=0.95-1.0$

$\mathrm{G}_{\mathrm{b}}=0.8-1.0$

\subsection{Dimension of the Scraper and the Tractive Force}

The model of the scraper used in this simulation is the scraper model 15SBW which is manufactured by Kokudo Koki Co. Ltd. The tractor is the bulldozer D7H which is manufactured by New Caterpillar Mitsubishi Co. Ltd. The maximum tractive force is based on this model. The dimension of the scraper and the maximum tractive force are listed in Table 1. Here, $A_{a}$ and $A_{b}$ show the cross sectional areas of the hydraulic cylinder for bore and rod side, respectively, D shows the width (refer to Figure 4).

Table 1 Dimension of the scraper

\begin{tabular}{|c|c|c|c|c|c|c|}
\hline $\mathrm{l}_{13}[\mathrm{~m}]$ & $1_{14}[\mathrm{~m}]$ & $1_{24}[\mathrm{~m}]$ & $1_{25}[\mathrm{~m}]$ & $1_{26}[\mathrm{~m}]$ & $\phi_{1}[$ degree $]$ & $\phi_{2}[$ degree $]$ \\
\hline 4.013 & 2.853 & 2.264 & 4.508 & 3.065 & 48.75 & 3 \\
\hline
\end{tabular}

\begin{tabular}{|c|c|c|c|c|c|}
\hline$\phi_{3}[$ degree $]$ & $\mathrm{D}[\mathrm{m}]$ & $\mathrm{b}[\mathrm{m}]$ & $\mathrm{A}_{\mathrm{a}}\left[\mathrm{m}^{2}\right]$ & $\mathrm{A}_{\mathrm{b}}\left[\mathrm{m}^{2}\right]$ & $\mathrm{F}_{\max }[$ ton $]$ \\
\hline 17.5 & $0.4 \mathrm{~m}$ & $2.8 \mathrm{~m}$ & 0.01767 & 0.01325 & 43.5 \\
\hline
\end{tabular}




\subsection{Feedback Gain}

All feedback gains are determined by trial and error method, and they are listed in Table 2

Table 2 Feed back gain

\begin{tabular}{|c|c|c|c|}
\hline $\mathrm{K}_{\mathrm{p}}\left[\mathrm{m}^{3} \cdot \mathrm{s}^{-1} \cdot \mathrm{rad}^{-1}\right]$ & $\mathrm{K}_{\mathrm{i}}\left[\mathrm{m}^{3} \cdot \mathrm{s}^{-2} \cdot \mathrm{rad}^{-1}\right]$ & $\mathrm{K}_{\mathrm{d}}\left[\mathrm{m}^{3} \cdot \mathrm{rad}^{-1}\right]$ & $\mathrm{K}_{\mathrm{f}}\left[\mathrm{m}^{3} \cdot \mathrm{s}^{-1} \cdot \mathrm{kg}^{-1}\right]$ \\
\hline 0.3 & 1.5 & 0.015 & $3 \times 10^{-7}$ \\
\hline
\end{tabular}

\subsection{Time Step of Calculation}

The time step of calculation in this simulation was determined with considering the general electric valve used in the actual machine, and it was set to be $0.2 \mathrm{sec}$.

\subsection{Speed of the Scraper}

During the work, it is desirable to keep the scraper speed constant. However, it is rather difficult to keep the moving speed of the scraper constant in the actual operation. Therefore, in this simulation, the speed of the scraper is given at random within the range of $0.9-1.0 \mathrm{~m} / \mathrm{s}$.

\subsection{Threshold Value in the Flattening Mode}

The threshold value in the flattening mode, $\tilde{\mathrm{F}}$ should be as close to the maximum tractive force, $F_{\max }$ as possible. However, if this value is set to be too close to the maximum tractive force, the possibility that the resistive force of excavation exceeds the maximum tractive force is extremely high. Therefore, the threshold value is assumed to be $\alpha \mathrm{F}_{\max }$ and $\alpha$ is determined as 0.6 by trial and error method. That is,

$$
\tilde{F}=\alpha \cdot F_{\max }=26.1 \text { ton }
$$

$\tilde{\mathrm{y}}$ is also determined as $2 \mathrm{~cm}$ by trial and error method.

\subsection{Physical Properties of the Soil}

Physical properties of the soil are listed in Table 3. Here, $\gamma$ is the density of the soil, $\delta$ is the friction angle between the blade and the soil, $\phi$ is the internal friction angle

Table 3 Physical properties of the soil

\begin{tabular}{|c|c|c|c|}
\hline$\gamma\left[\mathrm{kg} \cdot \mathrm{m}^{-3}\right]$ & $\mathrm{c}\left[\mathrm{kg} \cdot \mathrm{m}^{-2}\right]$ & $\phi[$ degree $]$ & $\delta[$ degree $]$ \\
\hline 1575 & 3000 & 32.5 & 21.7 \\
\hline
\end{tabular}

\subsection{Simulation Results}

Figure 7 shows a typical example of the simulation results. In this result, it is confirmed that the mode was changed from flattening to loading in the vicinity of $x=14 \mathrm{~m}$. It is often said that the accuracy of the work by the expert operator is about $\pm 5 \mathrm{~cm}$. On the other hand, the accuracy of this simulation is about $\pm 3 \mathrm{~mm}$. Furthermore, the fluctuating width of $\mathrm{F} / \mathrm{F}_{\max }$ is less than 0.8 (not over unity). That is, it was found that safety ratio $(\alpha=0.6)$ is suitable. Figure 7 shows that the flattening work is completed by the 2 nd work of the scraper. 


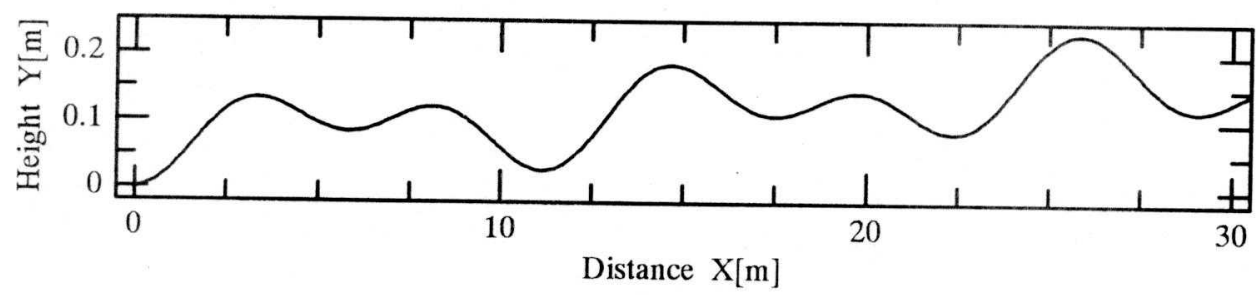

Shape of the initial ground

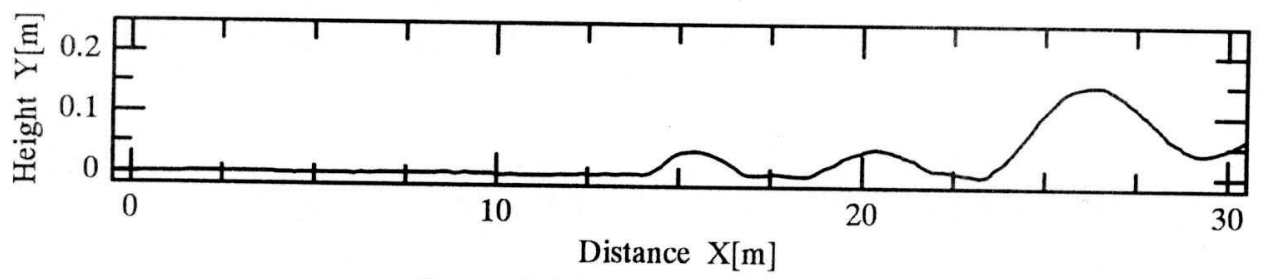

Shape of the ground by the 2 nd work

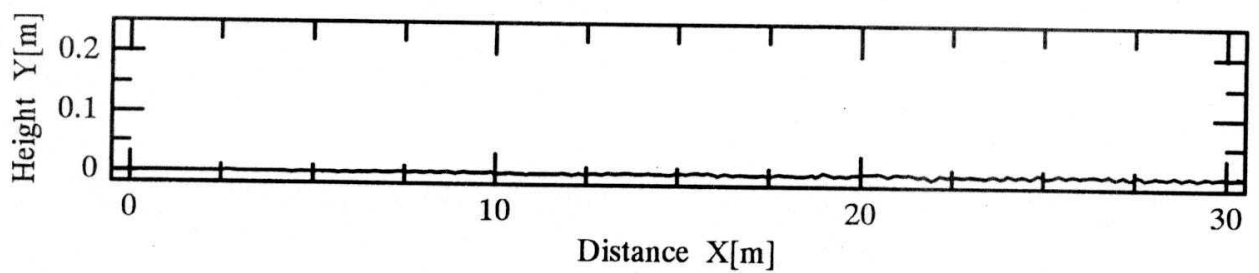

Shape of the ground by the 2nd work

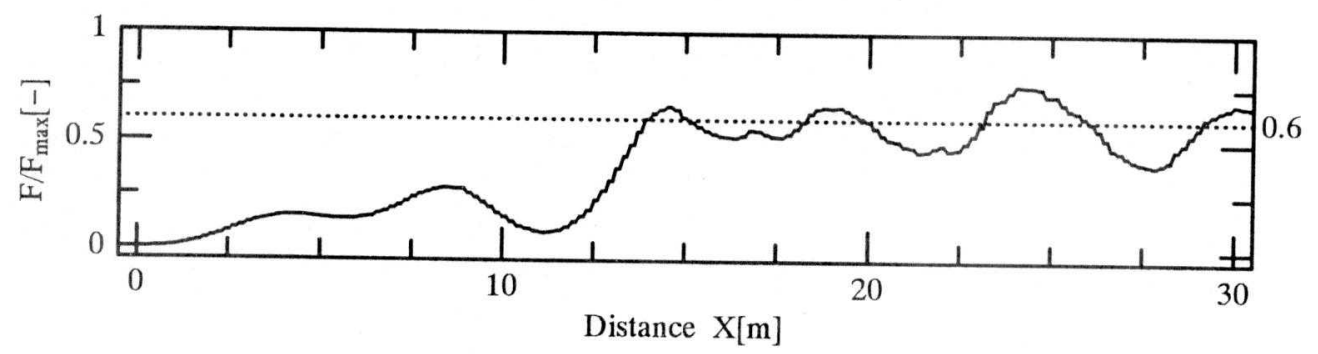

Fluctuation of $\mathrm{F} / \mathrm{F}_{\max }$ in the 1 st work

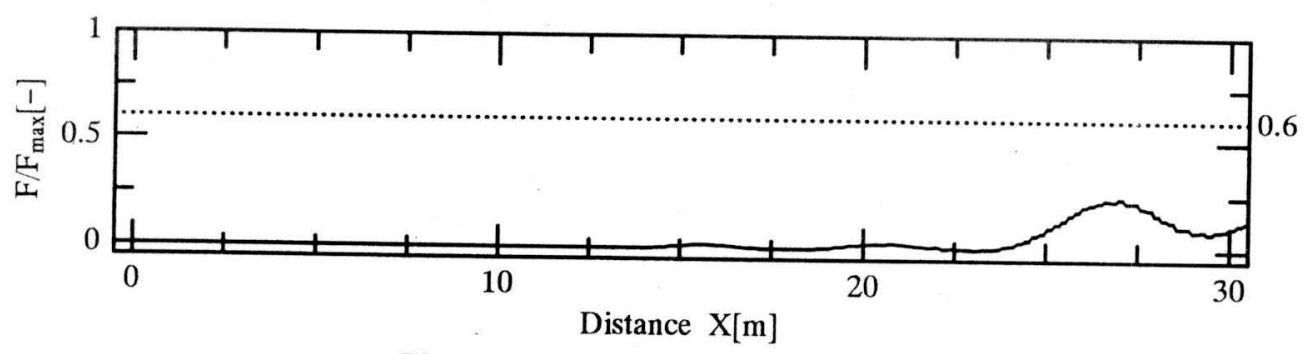

Fluctuation of $F / F_{\max }$ in the 2nd work

Fig. 7 An example of simulation results 


\section{CONCLUSIONS}

The motion controller of the cutting edge of the scraper was proposed for flattening and loading mode, and the simulation of flattening the ground was carried out. In result, it was confirmed that the accuracy of this simulation in the flattening mode by using the controller proposed here was about $\pm 3 \mathrm{~mm}$, which is much better than that of the expert operator. In the loading mode, the efficiency of the work was increased by controlling the height of the cutting edge so that the resistive force of excavation does not exceed the maximum tractive force.

\section{REFERENCES}

[1] J. Chiba and T. Takeda : Journal of the Society of Instrument and Control Engineers, Vol.21, No.8, pp.800-806, 1982.

[2] K. Date et al. : Proc. of the 2nd Symp. on Construction Robotics in Japan, pp.275-282, 1991.

[3] Y. Kikuchi et al. : Proc. of the 2nd Symp. on Construction Robotics in Japan, pp.283-290, 1991

[4] M. Hujitani et al. : Proc. of the 3rd Symp. on Construction Robotics in Japan, pp.283-290, 1993. 